\title{
BMJ Open Prevalence, pattern and determinants of chronic disease multimorbidity in Nepal: secondary analysis of a national survey
}

\author{
Raja Ram Dhungana (D) , ${ }^{1}$ Khem Bahadur Karki, ${ }^{2}$ Bihungum Bista, ${ }^{3}$ \\ Achyut Raj Pandey, ${ }^{4}$ Meghnath Dhimal (D) ${ }^{3}$ Mahesh K Maskey ${ }^{5}$
}

To cite: Dhungana RR, Karki KB, Bista B, et al. Prevalence, pattern and determinants of chronic disease multimorbidity in Nepal: secondary analysis of a national survey. BMJ Open 2021;11:e047665. doi:10.1136/ bmjopen-2020-047665

- Prepublication history and additional supplemental material for this paper are available online. To view these files, please visit the journal online (http://dx.doi.org/10.1136/ bmjopen-2020-047665)

Received 07 December 2020 Accepted 13 July 2021

Check for updates

(c) Author(s) (or their employer(s)) 2021. Re-use permitted under CC BY. Published by BMJ.

${ }^{1}$ Nepal Family Development Foundation, Lalitpur, Nepal

${ }^{2}$ Tribhuvan University Institute of Medicine, Maharajgunj, Nepal ${ }^{3}$ Nepal Health Research Council, Kathmandu, Nepal

${ }^{4}$ Abt Associates, Kathmandu, Nepal

${ }^{5}$ Nepal Public Health Foundation, Kathmandu, Nepal

Correspondence to Dr Raja Ram Dhungana; raja.dhungana@gmail.com

\section{ABSTRACT}

Objectives To assess the prevalence, pattern and determinants of non-communicable diseases (NCDs) multimorbidity in Nepal.

Design Secondary analysis of the data from the NCD survey 2018, which was conducted between 2016 and 2018.

Setting The data belong to the nationally representative survey, that selected the study samples from throughout Nepal using multistage cluster sampling.

Participants 8931 participants aged 20 years and older were included in the study.

Primary outcomes NCD multimorbidity (occurrence of two or more chronic conditions including hypertension, diabetes, chronic obstructive pulmonary disease, chronic kidney disease, coronary artery disease and cancer). Descriptive statistics, prevalence ratio and odds ratio were computed to assess pattern and determinants of multimorbidity.

Results Mean (SD) age was 46.7 years (14.9 years). The majority of the participants were women $(57.8 \%)$, without formal education (53.4\%) and from urban areas (51.5\%). Multimorbidity was present in $13.96 \%$ (95\% Cl: $12.9 \%$ to $15.1 \%)$. Hypertension and diabetes coexisted in 5.7\%. Age alcohol consumption, body mass index, non-high-density lipoprotein (non-HDL) level and rural-urban setting were significantly associated with multimorbidity.

Conclusion Multimorbidity was prevalent in particular groups or geographical areas in Nepal suggesting a need for coordinated and integrated NCD care approach for the management of multiplicative co-comorbid conditions.

\section{BACKGROUND}

Globally, non-communicable diseases (NCDs) are giving rise to enormous public health challenges. Recently, the coexistence of two and more NCDs (multimorbidity) has escalated the burden of NCDs globally. ${ }^{1-6}$ The prevalence of multimorbidity varies from $12 \%$ to $95 \%$ across different countries, ${ }^{7-9}$ clustering particularly in socioeconomically deprived areas. ${ }^{10}$

Effects of multimorbidity range from an individual to the health system level. In an
Strengths and limitations of this study

- This is the first nationally representative study to assess the prevalence, pattern and determinants of non-communicable disease (NCD) multimorbidity in Nepal.

- Data were collected from the national representative sample of 20 years and older adults in Nepal.

- Data relating to cancer are prone to self-reporting bias.

- Estimating the multimorbidity from only six NCDs is likely to underestimate its condition in Nepal.

individual, effects can stretch out from poor physical and mental health outcomes to high treatment burden for the management of multiple chronic diseases. ${ }^{211}$ Likewise, multiplications of the comorbid conditions could exert enormous pressure on the existing model of healthcare delivery that lacks coordination and integration of NCD services by increasing healthcare costs and workload. ${ }^{811} 12$

The major NCDs shared the common behavioural and metabolic risk factors such as physical inactivity, smoking, alcohol consumption and low fruit and vegetables and obesity, which are the leading contributors to burden of multimorbidity. ${ }^{13} 14$ Evidence shows that various social circumstances associated with income, education, occupation, gender and ethnicity also determine the distribution of NCDs and multimorbidity. ${ }^{291516}$ For example, multimorbidity comes about much earlier in life, up to 15 years earlier, among the people belonging to the poor socioeconomic status compared with their wealthier counterparts. ${ }^{4} 17$ Additionally, ageing, advancement of healthcare and increasing life expectancy are closely linked with NCDs and thus are also related to multimorbidity. ${ }^{215}$ 
Nepal, a lower-middle income country in South Asia (landlocked between China and India), hosts a multicultural, multiethnic (over 125 castes/ethnic groups), multilingual (129 first languages) and multireligious (over 10 religions) population of 28 million living mostly in rural areas. ${ }^{18} 19$ Recent epidemiological surveys indicated an increasing trend of prevalence of chronic conditions including hypertension (HTN) and diabetes (DM) in Nepal. ${ }^{20}$ For example, HTN increased from $21 \%$ to $25 \%$ between $2007^{21}$ and $2019,{ }^{20}$ and prevalence of DM rose from $3.6 \%$ to $5.8 \%$ between $2013^{22}$ and $2019 .{ }^{20}$ While the prevalence of NCDs is in a rising trend, more individuals are likely to acquire multimorbidity. However, no systematic investigation on NCD multimorbidity is available in Nepal. Detailed epidemiological information is essential for facilitating health system preparedness and response in terms of prevention and management of multimorbidity. Therefore, this study aimed to assess the prevalence, patterns and determinants of multimorbidity in Nepal.

\section{METHODS}

\section{Data source, study participants and sampling}

We used the data from the first nationally representative population-based NCDs survey in Nepal (shortly, NCD survey) ${ }^{23}$ The cross-sectional survey was conducted between 2016 and 2018. The purpose of the NCD survey was to estimate the prevalence of selected NCDs including HTN, DM, chronic obstructive pulmonary disease (COPD), chronic kidney disease (CKD), coronary artery disease $(\mathrm{CAD})$ and cancer $(\mathrm{CA})$ in Nepal.

The NCD survey applied a multistage cluster sampling method to select the participants aged 20 years and above from throughout Nepal. Details of the sampling procedure and survey reports are available elsewhere. ${ }^{23}{ }^{24}$ For our study purpose, we included the data from 8931 participants those having information on six NCDs.

\section{Data collection}

The NCD survey collected information on HTN, DM, $\mathrm{COPD}, \mathrm{CKD}, \mathrm{CAD}$ and $\mathrm{CA}$. The survey team recorded three readings of systolic and diastolic blood pressure and used the average of the last two measurements of blood pressure to define HTN as the condition of having systolic blood pressure of $\geq 140 \mathrm{~mm} \mathrm{Hg}$ and/or diastolic blood pressure of $\geq 90 \mathrm{~mm} \mathrm{Hg}$ and/or the use of antihypertensive medication. The survey considered the participants as diabetics if they had raised fasting glucose $(\geq 126 \mathrm{mg} / \mathrm{dL})$ or raised postprandial blood glucose level $(\geq 200 \mathrm{mg} / \mathrm{dL})$ or the participant was on antidiabetic medication. COPD was diagnosed based on the ratio of $\mathrm{FEV}_{1}$ to $\mathrm{FVC}$ and $\mathrm{CKD}$ was confirmed using urinary albumin to creatinine ratio and/or measurement of serum creatinine/estimated glomerular filtration rate. ${ }^{23}$ For diagnosing $\mathrm{CAD}$, the survey used the (a) information on self-reported admission for myocardial infarction, percutaneous coronary angioplasty or coronary artery bypass surgery; (b) ECG test and (c) responses on the Rose Angina questionnaire. ${ }^{25}$ Details are given in the survey report. ${ }^{23} \mathrm{CA}$ diagnosis was confirmed as informed by the participants. Details on operational definitions of the study variables are given in the survey report ${ }^{23}$ and online supplemental file 1 .

The NCD survey also collected information related to sociodemographic characteristics, household income, smoking, alcohol consumption, body mass index (BMI) and lipid. We extracted the data both on the outcome (HTN, DM, COPD, CKD, CAD and CA) and study variables (sociodemographic characteristics, smoking, alcohol consumption, overweight/obesity and high non-highdensity lipoprotein (non-HDL)) and defined them as per the survey criteria to assess the burden of NCD multimorbidity in Nepal. Multimorbidity was defined as the presence of two and more NCDs. ${ }^{10}$

\section{Data analysis}

We used the NCD survey information on primary sample units, strata and sampling weight to construct the complex survey weight and performed data analysis using STATA software V.16.1 (Stata Corporation). All estimates are presented with $95 \%$ CIs. Geographical distribution and clustering of NCDs are presented graphically. To better understand the independent effects of covariates on multimorbidity, we considered the number of NCDs that occurred in each participant as count data and applied multiple Poisson regression and reported the adjusted relative risk of having a number of NCDs.

For multivariable analysis, we created the hierarchy of the variables as level 1-distant factors (all sociodemographic variables: age, gender, marital status, ethnicity, religion, education, occupation, household income, Province and residence), level 2-intermediate factors (behavioural factors: smoking and alcohol consumption) and level 3-immediate factors (metabolic factors: BMI and non-HDL) and applied hierarchical modelling using a series of stepwise (backward selection, selection criteria: $\mathrm{p}$ value $<0.2)$ logistic regression. Hierarchical approach in multivariable data analysis is one of the improved methods for estimating the effect of explanatory variables if there are complex hierarchical inter-relationships between these variables. ${ }^{26}$ For sensitivity analysis, we imputed the 568 missing data on non-HDL using the logistic model and replicated the analysis like in the main analysis. A p value $<0.05$ is considered statistically significant.

\section{Patient and public involvement}

This is the secondary data analysis of the data from the NCD survey. Patients were not involved in the design or conduct of this study, and nor were members of the general public.

\section{RESULTS}

\section{Sociodemographic characteristics}

The mean (SD) age was 46.7 years (14.9 years). The majority of the participants were women (57.8\%), married $(88.5 \%)$, Hindu (88.9\%), without formal education $(53.4 \%)$ and from urban areas $(51.5 \%)$ (table 1$)$. 


\begin{tabular}{|c|c|c|c|c|}
\hline Categories & & Male (\%) & Female (\%) & Total (\%) \\
\hline \multirow[t]{5}{*}{ Age groups } & $<30$ years & 5.83 & 9.51 & 15.34 \\
\hline & $30-44$ years & 10.38 & 17.87 & 28.25 \\
\hline & $45-59$ years & 15.79 & 16.84 & 32.63 \\
\hline & $60-74$ years & 11.48 & 9.12 & 20.60 \\
\hline & $\geq 75$ years & 2.12 & 1.05 & 3.18 \\
\hline \multirow{4}{*}{$\begin{array}{l}\text { Marital } \\
\text { status }\end{array}$} & Never married & 2.75 & 1.85 & 4.60 \\
\hline & $\begin{array}{l}\text { Currently married/ } \\
\text { cohabiting }\end{array}$ & 41.55 & 46.93 & 88.48 \\
\hline & Separated/divorced & 0.15 & 0.45 & 0.60 \\
\hline & Widowed & 1.15 & 5.17 & 6.32 \\
\hline \multirow[t]{6}{*}{ Ethnicity } & Dalit & 3.94 & 5.52 & 9.46 \\
\hline & Disadvantaged Janajatis & 9.45 & 11.29 & 20.74 \\
\hline & $\begin{array}{l}\text { Disadvantaged non-Dalit } \\
\text { Terai caste }\end{array}$ & 8.63 & 8.55 & 17.18 \\
\hline & Religious minorities & 1.53 & 1.26 & 2.79 \\
\hline & $\begin{array}{l}\text { Relatively advantaged } \\
\text { Janajatis }\end{array}$ & 7.90 & 9.35 & 17.25 \\
\hline & Upper caste groups & 14.16 & 18.43 & 32.59 \\
\hline \multirow[t]{5}{*}{ Religion } & Hindu & 40.27 & 48.64 & 88.91 \\
\hline & Buddhist & 2.57 & 2.84 & 5.41 \\
\hline & Muslim & 1.91 & 1.76 & 3.67 \\
\hline & Christian & 0.32 & 0.44 & 0.76 \\
\hline & Kirat and other & 0.54 & 0.71 & 1.25 \\
\hline \multirow[t]{6}{*}{ Education } & No education & 17.10 & 36.25 & 53.35 \\
\hline & Primary education & 7.34 & 3.93 & 11.27 \\
\hline & $\begin{array}{l}\text { Lower secondary } \\
\text { education }\end{array}$ & 5.22 & 3.42 & 8.64 \\
\hline & Secondary education & 8.31 & 5.67 & 13.98 \\
\hline & Intermediate or plus 2 & 3.59 & 2.95 & 6.54 \\
\hline & Graduate and above & 4.05 & 2.18 & 6.22 \\
\hline \multirow[t]{9}{*}{ Occupation } & Government employee & 2.72 & 1.10 & 3.82 \\
\hline & $\begin{array}{l}\text { Non-government } \\
\text { employee }\end{array}$ & 2.95 & 1.31 & 4.27 \\
\hline & Self-employed/business & 8.44 & 3.55 & 11.99 \\
\hline & Agriculture (commercial) & 20.99 & 16.83 & 37.82 \\
\hline & Labour & 3.13 & 0.85 & 3.99 \\
\hline & Student & 1.24 & 0.98 & 2.23 \\
\hline & Homemaker & 1.27 & 25.96 & 27.24 \\
\hline & Unemployed & 2.10 & 3.19 & 5.29 \\
\hline & Retired & 2.74 & 0.62 & 3.36 \\
\hline \multirow{5}{*}{$\begin{array}{l}\text { Income } \\
\text { quintile }\end{array}$} & Lowest & 9.78 & 12.47 & 22.25 \\
\hline & Second & 8.59 & 10.38 & 18.96 \\
\hline & Middle & 6.87 & 8.61 & 15.48 \\
\hline & Fourth & 10.99 & 12.29 & 23.29 \\
\hline & Highest & 9.60 & 10.42 & 20.02 \\
\hline \multirow[t]{7}{*}{ Province } & Province 1 & 7.49 & 9.30 & 16.78 \\
\hline & Province 2 & 9.37 & 9.03 & 18.40 \\
\hline & Bagmati & 10.60 & 12.98 & 23.58 \\
\hline & Gandaki & 3.92 & 5.51 & 9.43 \\
\hline & Lumbini & 7.91 & 8.97 & 16.88 \\
\hline & Karnali & 2.12 & 3.08 & 5.20 \\
\hline & Sudurpaschim & 4.21 & 5.53 & 9.74 \\
\hline
\end{tabular}

Continued
Table 1 Continued

\begin{tabular}{lllll}
\hline Categories & Male (\%) & Female (\%) & Total (\%) \\
\hline \multirow{2}{*}{ Residence } & Rural & 20.97 & 27.55 & 48.52 \\
& Urban & 21.19 & 30.29 & 51.48 \\
\hline
\end{tabular}

\section{Prevalence of NCD multimorbidity}

The prevalence of NCD multimorbidity was $13.96 \%$ (95\% CI: $12.9 \%$ to $15.1 \%$ ). Participants at older ages, men, religious minorities, those without formal education and obese had a higher prevalence of multimorbidity (table 2).

In geographic distribution, Bagmati province had the highest proportion of multimorbidity (figure 1). The prevalence of multimorbidity also varied by urban and rural settings, where more participants from urban than rural had multimorbidity.

\section{Pattern of multimorbidity}

Among the participants having multimorbidity, $80.1 \%$ had two NCDs, $17.4 \%$ were with three NCDs and $2.5 \%$ reported having four and more NCDs. The clustering of NCDs significantly varied with age and gender (figure 2), where NCDs were more likely to occur at old ages and in men (online supplemental file 2).

The most common pair of cooccurrences of NCDs was HTN and DM, followed by HTN and COPD, and HTN and CKD (figure 3). The triad 'HTN, DM and CKD' was present in $1.4 \%$.

\section{Factors associated with multimorbidity}

Age was significantly associated with NCD multimorbidity. The odds of having multimorbidity were 9.4 times for 30-44 years, 27.1 times for $45-59$ years and 52.8 for 60-74 years compared with the below 30 years of age group (online supplemental file 3 ). The probability of occurring multimorbidity was significantly higher in overweight/obesity, alcohol users, urban areas and those who had high non-HDL compared with others (figure 4). The magnitude and direction of the estimates from the imputed dataset were similar to the main analysis.

\section{DISCUSSION}

Our study demonstrated the high burden of NCD multimorbidity in Nepal particularly affecting the elderly, obese, alcohol users, religious minorities, higher-income group and urban residents. Our study reports the very first findings on NCD multimorbidity in Nepal, which may inform the stakeholders on its status, patterns and distribution across Nepal.

The prevalence of NCD multimorbidity in our study was $13.96 \%$. The finding is higher than the rate reported in South Asian countries, India and Pakistan (9.4\%), ${ }^{27}$ and Bangladesh (8.4\%), ${ }^{28}$ consistent with the prevalence reported in Canada $(12.9 \%),{ }^{13}$ Switzerland $(14.5 \%)^{29}$ and China $(14 \%)^{30}$ and lower than that of Australia $(47.1 \%),{ }^{31}$ Denmark $(39.7 \%)$, Brazil $(29 \%),{ }^{32}$ England 


\begin{tabular}{|c|c|c|c|}
\hline \multirow[b]{2}{*}{ Categories } & & \multicolumn{2}{|c|}{ Multimorbidity } \\
\hline & & $\%$ & $95 \% \mathrm{Cl}$ \\
\hline \multirow[t]{5}{*}{ Age groups } & $<30$ years & 0.81 & 0.44 to 1.5 \\
\hline & $30-44$ years & 6.23 & 5.2 to 7.45 \\
\hline & $45-59$ years & 16.75 & 15.1 to 18.54 \\
\hline & $60-74$ years & 26.01 & 23.39 to 28.82 \\
\hline & $\geq 75$ years & 39.56 & 32.94 to 46.6 \\
\hline \multirow[t]{2}{*}{ Gender } & Female & 12.02 & 10.77 to 13.38 \\
\hline & Male & 16.29 & 14.83 to 17.86 \\
\hline \multirow[t]{4}{*}{ Marital status } & Never married & 2.89 & 1.48 to 5.56 \\
\hline & Currently married/cohabiting & 13.9 & 12.79 to 15.09 \\
\hline & Separated/divorced & 14.03 & 6.74 to 26.93 \\
\hline & Widowed & 22.71 & 18.98 to 26.92 \\
\hline \multirow[t]{6}{*}{ Ethnicity } & Dalit & 14.26 & 11.77 to 17.17 \\
\hline & Disadvantaged Janajatis & 11.4 & 9.79 to 13.24 \\
\hline & $\begin{array}{l}\text { Disadvantaged non-Dalit } \\
\text { Terai caste }\end{array}$ & 14.69 & 12.36 to 17.38 \\
\hline & Religious minorities & 21.14 & 15.98 to 27.41 \\
\hline & $\begin{array}{l}\text { Relatively advantaged } \\
\text { Janajatis }\end{array}$ & 18.45 & 15.52 to 21.79 \\
\hline & Upper caste groups & 12.14 & 10.64 to 13.83 \\
\hline \multirow[t]{5}{*}{ Religion } & Hindu & 13.66 & 12.54 to 14.87 \\
\hline & Buddhist & 15.29 & 11.53 to 20 \\
\hline & Muslim & 20.06 & 15.49 to 25.58 \\
\hline & Christian & 9.34 & 4.17 to 19.63 \\
\hline & Kirat and others & 14.49 & 8.25 to 24.21 \\
\hline \multirow[t]{6}{*}{ Education } & No education & 15.85 & 14.45 to 17.36 \\
\hline & Primary education & 14.32 & 11.9 to 17.13 \\
\hline & Lower secondary education & 10.8 & 8.38 to 13.81 \\
\hline & Secondary education & 11.91 & 9.72 to 14.52 \\
\hline & Intermediate or plus 2 & 10.99 & 8.15 to 14.66 \\
\hline & Graduate and above & 9.28 & 6.87 to 12.42 \\
\hline \multirow[t]{9}{*}{ Occupation } & Government employee & 16.69 & 12.29 to 22.26 \\
\hline & Non-government employee & 12.79 & 9.07 to 17.75 \\
\hline & Self-employed/business & 15.98 & 12.95 to 19.56 \\
\hline & Agriculture (commercial) & 11.78 & 10.37 to 13.34 \\
\hline & Labour & 10.23 & 7.36 to 14.03 \\
\hline & Student & 0.37 & 0.09 to 1.47 \\
\hline & Homemaker & 14.81 & 13.01 to 16.83 \\
\hline & Unemployed & 18.27 & 14.35 to 22.98 \\
\hline & Retired & 29.71 & 24.55 to 35.45 \\
\hline \multirow[t]{5}{*}{ Income quintile } & Lowest & 11.5 & 9.91 to 13.32 \\
\hline & Second & 11.73 & 9.97 to 13.75 \\
\hline & Middle & 13.2 & 11.16 to 15.55 \\
\hline & Fourth & 16.96 & 14.83 to 19.32 \\
\hline & Highest & 15.87 & 13.75 to 18.24 \\
\hline \multirow[t]{2}{*}{ Residence } & Rural & 10.89 & 9.69 to 12.23 \\
\hline & Urban & 17.03 & 15.32 to 18.89 \\
\hline \multirow{2}{*}{$\begin{array}{l}\text { Smoking } \\
\text { (current) }\end{array}$} & No & 13.9 & 12.71 to 15.19 \\
\hline & Yes & 14.17 & 12.37 to 16.19 \\
\hline
\end{tabular}

Continued

\section{Table 2 Continued}

\begin{tabular}{llll}
\hline & & \multicolumn{2}{c}{ Multimorbidity } \\
\cline { 3 - 4 } Categories & & $\%$ & $95 \% \mathrm{Cl}$ \\
\hline Alcohol & No & 13.28 & 12.11 to 14.56 \\
consumption & Yes & 15.91 & 14.08 to 17.92 \\
Weight & Underweight $\left(<18.5 \mathrm{~kg} / \mathrm{m}^{2}\right)$ & 12.26 & 9.82 to 15.21 \\
& Normal $\left(18.5-24.9 \mathrm{~kg} / \mathrm{m}^{2}\right)$ & 10.91 & 9.87 to 12.05 \\
& Overweight $\left(25-29.9 \mathrm{~kg} / \mathrm{m}^{2}\right)$ & 20.74 & 18.32 to 23.38 \\
& Obese $\left(\geq 30 \mathrm{~kg} / \mathrm{m}^{2}\right)$ & 30.28 & 25.48 to 35.55 \\
High non-HDL & No $(<130 \mathrm{mg} / \mathrm{dL})$ & 11.5 & 10.4 to 12.7 \\
& Yes $(\geq 130 \mathrm{mg} / \mathrm{dL})$ & 18.73 & 16.87 to 20.75 \\
\hline
\end{tabular}

Non-HDL, Non-high-density lipoprotein.

$(27.2 \%)^{3}$ and Vietnam (16.4\%).$^{33}$ A systematic review that computed a pooled estimate of multimorbidity from 18 high-income countries and 31 low/middle-income countries had found the prevalence of multimorbidity to be $33.1 \% .^{34}$ As the prevalence of chronic conditions tends to differ across different countries owing to differences in dietary practices, lifestyle, alcohol consumption, tobacco use and level of physical activity, among others, it is not uncommon for multimorbidity to vary across countries. Some of these disparities could be because of the differences in the methodology used in individual study. For example, prevalence of multimorbidity also depends on the number of diseases considered in the study, population under study and selection of participants.

The most common pair of cooccurrences of NCDs was HTN and DM (5.7\%). The prevalence of comorbid DM and HTN was two times as high as that we reported (2\%) in 2013 in Nepal, suggesting an increasing burden of DM and HTN comorbidity over the years. ${ }^{35}$ The prevalence of comorbid DM and HTN was found to be $4.5 \%$ in India ${ }^{36}$ and $3 \%$ in Bangladesh. ${ }^{37}$ Similarly, a study by Harrison $e t$ $a l$ in Australia had found that the cooccurrence of HTN and DM was $4.1 \% .^{31}$ The higher cooccurrence of DM and HTN or the comorbid condition could be because both conditions are more prevalent in society and also share common risk factors.

The prevalence of multimorbidity was found to be slightly higher among men in our study. The prevalence of multimorbidity was $16 \%$ in men and $12 \%$ in women.

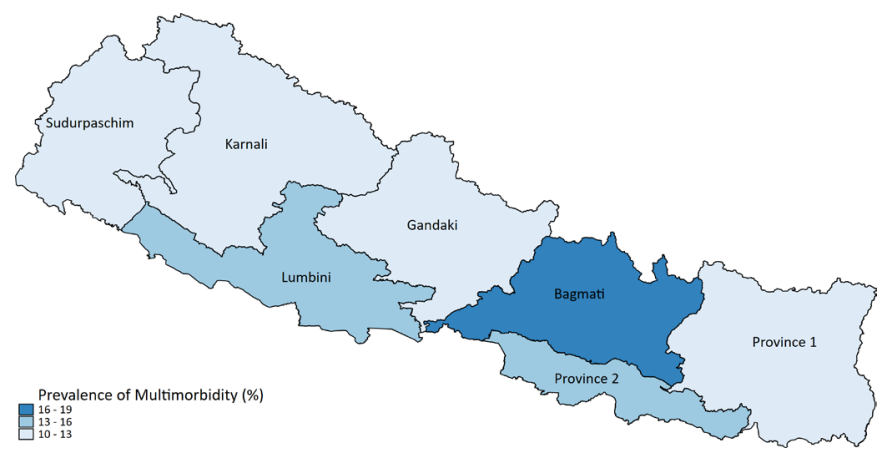

Figure 1 Distribution of multimorbidity by Province. 


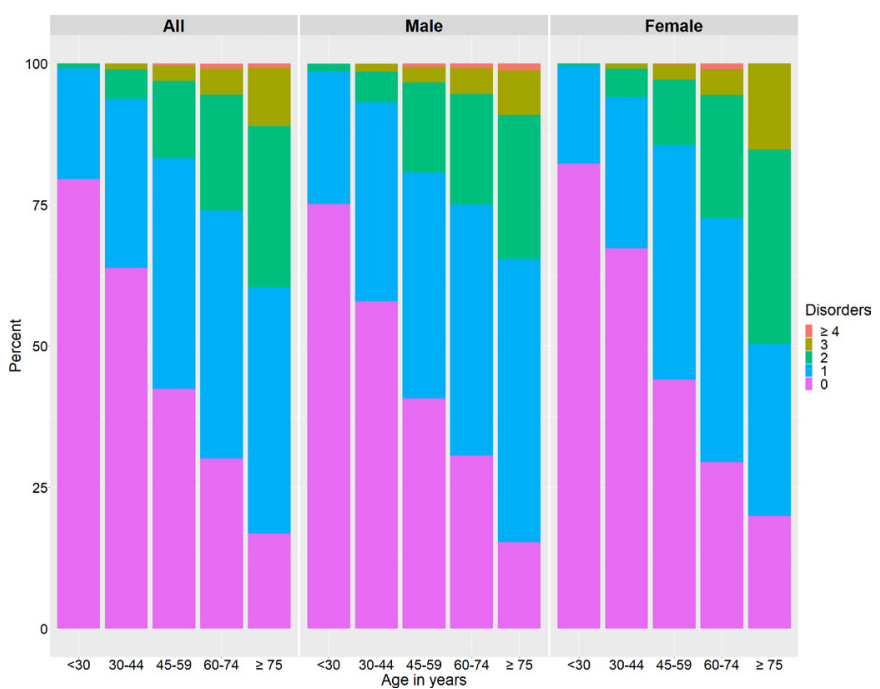

Figure 2 Clustering of NCDs by gender. Note: the prevalence of NCDs was likely to increase with ageing and was comparatively higher in men than women. Interestingly, compared with the men of the same age group, women of age 45 years and younger were less likely to have NCDs, whereas women of age $\geq 75$ years had higher prevalence of living with at least two NCDs (multimorbidity). NCDs, noncommunicable diseases.

After adjusting age, the difference in prevalence between men and women was not significant. Like our finding, one of the systematic reviews showed no statistically significant difference in the pooled prevalence of multimorbidity by gender though the nine of the studies that were reviewed reported a higher rate of multimorbidity in women than in men. ${ }^{9}$ Likewise, the prevalence of multimorbidity was $14.8 \%$ in men and $14.3 \%$ in women in Switzerland, ${ }^{29}$ and $17.2 \%$ in men and $15.5 \%$ in women in Vietnam, indicating no disparity in multimorbidity in-between. ${ }^{33}$

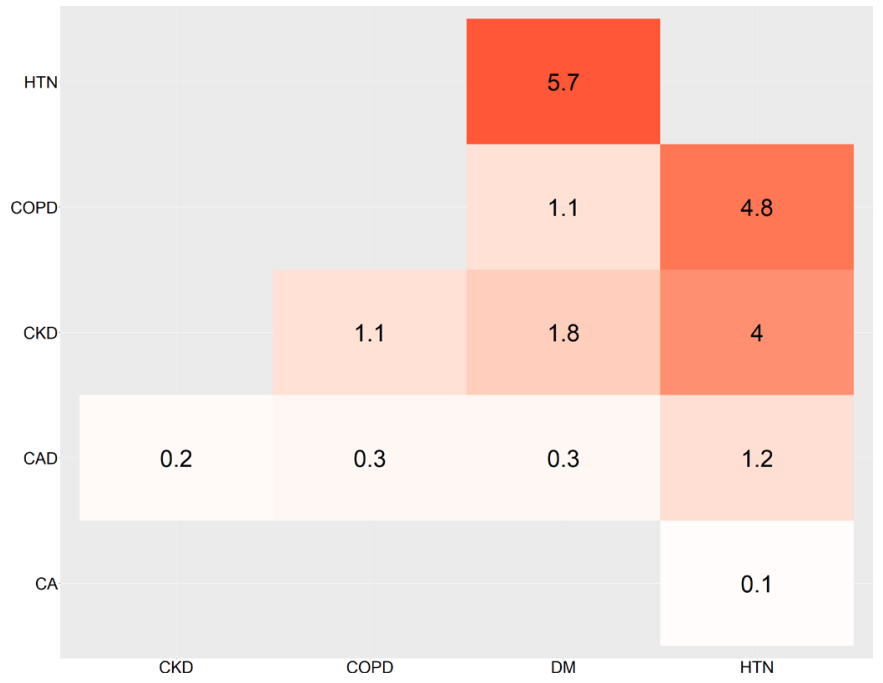

Figure 3 Cooccurrence of NCDs. Cooccurrence of six major NCDs given in per cent. CA, cancer; CAD, coronary artery disease; CKD, chronic kidney disease; COPD, chronic obstructive pulmonary disease; DM, diabetes; HTN, hypertension; NCDs, non-communicable diseases.

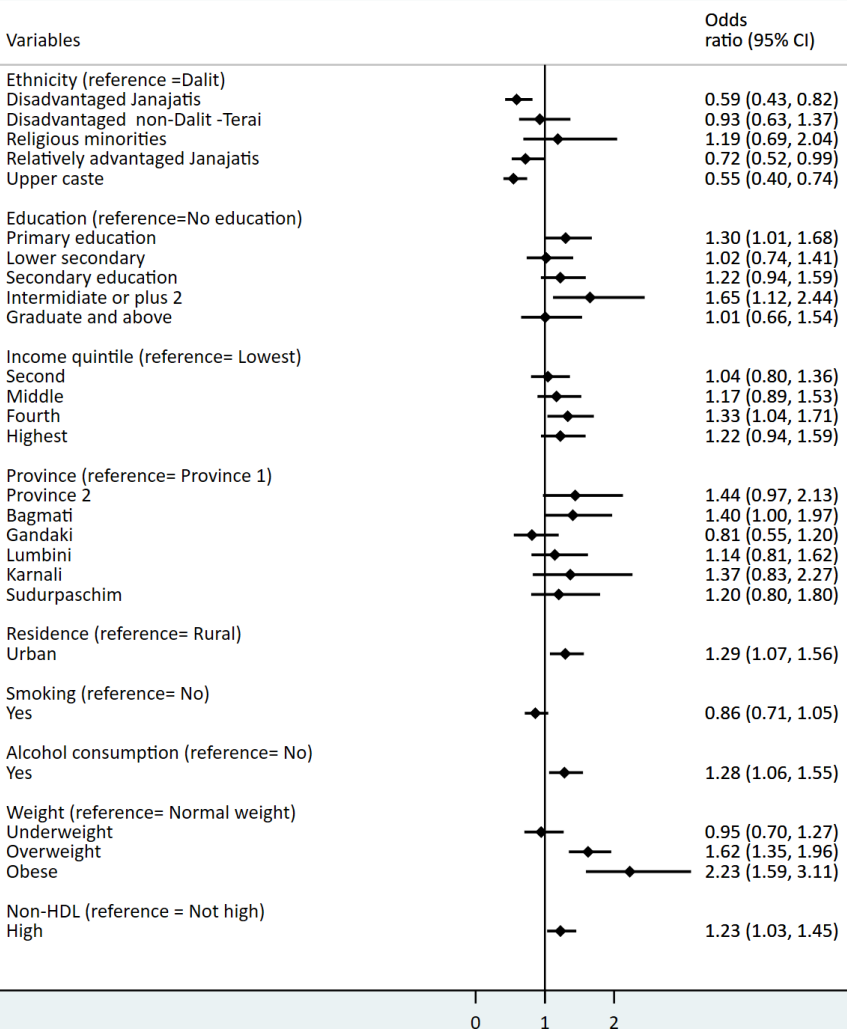

Figure 4 Factor associated with multimorbidity. OR was estimated from the hierarchical logistic regression models. Details of output are given in online supplemental file 2. NonHDL, non-high-density lipoprotein.

Multiple studies conducted in different setting have revealed age as a determinant of multimorbidity with the condition being more common with increasing age group. ${ }^{5938}$ The prevalence of multimorbidity was $0.81 \%$ among participants of age below 30 years and $39.5 \%$ among participants of age 75 years or above. In a similar study in Australia, the prevalence of multimorbidity was found to be $1.7 \%$ in participants of age 20-29 years, $33.6 \%$ among participants of age $70-79$ years and $37.7 \%$ in participants of age 80 years which also indicates that the multimorbidity increases with increasing age. ${ }^{29}$ In another study in the USA, the prevalence of multimorbidity was found to be $67 \%$ among those above 65 years and $71 \%$ among those above 75 years of age. ${ }^{39}$ As most of the NCDs are more common in the older age group, there could have been a higher probability of cooccurrence and thus leading to multimorbidity.

We found that urban area and Bagmati province (capital) had a higher prevalence of multimorbidity. This could be linked to the high burden of NCD risk factors in those areas. Recent surveys suggested that smoking, alcohol consumption, physical inactivity, high salt intake and obesity were more prevalent in Bagmati province and urban areas than others. ${ }^{20}{ }^{40}$ Likewise, alcohol consumption, one of the well-established NCD risk factors was also significantly associated with multimorbidity.

In our study, the odds of having multimorbidity was approximately threefolds higher in obese compared with 
normal-weight participants. Similar findings were also reported in studies by Agborsangaya et al ${ }^{14}$ and Khan et $a l^{28}$ where the odds of having multimorbidity was twofolds higher in obese. A higher risk of multimorbidity among the obese population could be because it is one of the most common risk factors shared among NCDs. This study also found that high non-HDL cholesterol, a strong predictor of cardiovascular diseases, ${ }^{41}$ was also significantly associated with multimorbidity.

This is the first study to assess the burden of multimorbidity in Nepal. Findings from the nationally representative study could have a high policy implication in terms of tackling the growing burden of multimorbidity in Nepal. Our study found that NCD multimorbidity is prevalent in Nepal. Higher prevalence of multimorbidity means more frequent hospital consultations and more hospitalisations. ${ }^{356}$ For example, Schneider et $a t^{6}$ reported that the patients with three or more chronic conditions use 25 times more hospital beds than peers without any chronic conditions. As higher proportion of healthcare encounters is likely to occur because of multimorbidity, appropriate training of the health facilities at peripheral level and development of an effective referral system could be useful in resource constraint setting like Nepal.

Likewise, with the growing burden of multimorbidity, health system also needs to prepare for dealing with an additional number of health facility visits in Nepal. The current health system organisation largely focuses on preventing and managing maternal and child health conditions. It requires a degree of reorganisation to deal with the increasing burden of NCDs and multimorbidity. There are several evidence-based models which are in practice for the management of multimorbidity globally. Sustainable integrated chronic care models for multimorbidity: delivery, financing and performance is an example of an innovative framework that suggests the integration of care at micro-level, meso-level and macro-level according to six pillars of health system: service delivery, leadership and governance, workforce, financing, technologies and medical products and information and research. ${ }^{42}$ The strategies, however, should be specific to the Nepalese context and backed by evidence on health benefit and cost-effectiveness as the most common comorbid conditions could vary from one country to another.

This study has some limitations. The use of selfreported data for CA diagnosis might have underestimated the prevalence of CA in the original study, affecting the current study findings. Likewise, our study could not include other several comorbid conditions such as mental disorders and degenerative diseases and possibly underestimated the burden of multimorbidity in Nepal. For that, a national representative survey encompassing the majority of the common NCDs is recommended.

\section{CONCLUSIONS}

This study demonstrated that NCD multimorbidity is prevalent and disproportionately distributed across different socioeconomic and demographic strata in Nepal. Growing prevalence of multimorbidity indicates an urgency for the health system to prepare and respond to the inevitable health threats and economic burden in Nepal.

\section{Twitter Raja Ram Dhungana @rajadhungana}

Acknowledgements We would like to thank Nepal Health Research Council for sharing the data. We appreciate all the participants for their great contribution to the study by sharing the information.

Contributors RRD and KBK conceptualised the study. RRD analysed the data. RRD $B B$ and ARP interpreted the findings and prepared the first draft of the manuscript. $\mathrm{KBK}, \mathrm{MD}$ and MKM interpreted the findings and revised the first draft of the manuscript. All authors read and approved the final manuscript. KBK is the co-first author.

Funding The authors have not declared a specific grant for this research from any funding agency in the public, commercial or not-for-profit sectors.

Map disclaimer The inclusion of any map (including the depiction of any boundaries therein), or of any geographic or locational reference, does not imply the expression of any opinion whatsoever on the part of BMJ concerning the legal status of any country, territory, jurisdiction or area or of its authorities. Any such expression remains solely that of the relevant source and is not endorsed by BMJ. Maps are provided without any warranty of any kind, either express or implied.

Competing interests None declared.

Patient consent for publication Not required.

Ethics approval The NCD survey obtained ethical approval from the Ethical Review Board of Nepal Health Research Council (ethical approval ID: nr. 110/2016). Informed consent was obtained from the study participants ensuring voluntary participation, privacy and confidentiality.

Provenance and peer review Not commissioned; externally peer reviewed.

Data availability statement Data used in the study are reposited in Nepal Health Research Council and are available from the council upon a reasonable request to the Council.

Supplemental material This content has been supplied by the author(s). It has not been vetted by BMJ Publishing Group Limited (BMJ) and may not have been peer-reviewed. Any opinions or recommendations discussed are solely those of the author(s) and are not endorsed by BMJ. BMJ disclaims all liability and responsibility arising from any reliance placed on the content. Where the content includes any translated material, BMJ does not warrant the accuracy and reliability of the translations (including but not limited to local regulations, clinical guidelines, terminology, drug names and drug dosages), and is not responsible for any error and/or omissions arising from translation and adaptation or otherwise.

Open access This is an open access article distributed in accordance with the Creative Commons Attribution 4.0 Unported (CC BY 4.0) license, which permits others to copy, redistribute, remix, transform and build upon this work for any purpose, provided the original work is properly cited, a link to the licence is given, and indication of whether changes were made. See: https://creativecommons.org/ licenses/by/4.0/.

\section{ORCID iDs}

Raja Ram Dhungana http://orcid.org/0000-0002-9610-6306

Meghnath Dhimal http://orcid.org/0000-0001-7176-7821

\section{REFERENCES}

1 Wild S, Roglic G, Green A, et al. Global prevalence of diabetes: estimates for the year 2000 and projections for 2030. Diabetes Care 2004;27:1047-53.

2 Koroukian SM, Schiltz NK, Warner DF, et al. Multimorbidity: constellations of conditions across subgroups of midlife and older individuals, and related Medicare expenditures. J Comorb 2017;7:33-43. 
3 Cassell A, Edwards D, Harshfield A, et al. The epidemiology of multimorbidity in primary care: a retrospective cohort study. Br J Gen Pract 2018;68:e245-51.

4 Huntley AL, Johnson R, Purdy S, et al. Measures of multimorbidity and morbidity burden for use in primary care and community settings: a systematic review and guide. Ann Fam Med 2012:10:134-41.

5 Salisbury C, Johnson L, Purdy S, et al. Epidemiology and impact of multimorbidity in primary care: a retrospective cohort study. Br J Gen Pract 2011;61:e12-21.

6 Schneider KM, O'Donnell BE, Dean D. Prevalence of multiple chronic conditions in the United States' Medicare population. Health Qual Life Outcomes 2009;7:82.

7 Garin N, Koyanagi A, Chatterji S, et al. Global multimorbidity patterns: a cross-sectional, population-based, multi-country study. $J$ Gerontol A Biol Sci Med Sci 2016;71:205-14.

8 Oni T, McGrath N, BeLue R, et al. Chronic diseases and multimorbidity - a conceptual modification to the WHO ICCC model for countries in health transition. BMC Public Health 2014;14:1-7.

9 Violan C, Foguet-Boreu Q, Flores-Mateo G, et al. Prevalence, determinants and patterns of multimorbidity in primary care: a systematic review of observational studies. PLoS One 2014:9:e102149.

10 Barnett K, Mercer SW, Norbury M, et al. Epidemiology of multimorbidity and implications for health care, research, and medical education: a cross-sectional study. Lancet 2012;380:37-43.

11 Thavorn K, Maxwell CJ, Gruneir A, et al. Effect of socio-demographic factors on the association between multimorbidity and healthcare costs: a population-based, retrospective cohort study. BMJ Open 2017;7:e017264.

12 Wolff JL, Starfield B, Anderson G. Prevalence, expenditures, and complications of multiple chronic conditions in the elderly. Arch Intern Med 2002;162:2269-76.

13 Roberts KC, Rao DP, Bennett TL, et al. Prevalence and patterns of chronic disease multimorbidity and associated determinants in Canada. Health Promot Chronic Dis Prev Can 2015;35:87-94.

14 Agborsangaya CB, Ngwakongnwi E, Lahtinen M, et al. Multimorbidity prevalence in the general population: the role of obesity in chronic disease clustering. BMC Public Health 2013:13:1161.

15 Wagner $\mathrm{K}-\mathrm{H}$, Brath $\mathrm{H}$. A global view on the development of non communicable diseases. Prev Med 2012;54(Suppl):S38-41.

16 Alwan A. Global status report on noncommunicable diseases 2010. World Health Organization, 2011.

17 Mercer SW, Zhou Y, Humphris GM, et al. Multimorbidity and socioeconomic deprivation in primary care consultations. Ann Fam Med 2018;16:127-31.

18 The World Bank Group. Population, total - Nepal. Secondary Population, total - Nepal, 2020. Available: https://data.worldbank. org/indicator/SP.POP.TOTL?locations=NP

19 Central Bureau Of Statistics (CBS) Nepal. National population and housing census 2011. Kathmandu: CBS, 2012.

20 Dhimal M, Bista B, Saroj B. Non communicable diseases risk factors: steps survey Nepal 2019. Nepal Health Research Council (NHRC), 2019.

21 World Health Organisation. Stepwise approach to chronic disease risk factor surveillance: 2007 steps survey report, 2008. Available: https://www.who.int/ncds/surveillance/steps/nepal/en/

22 Aryal KK, Neupane S, Mehata S. Non communicable diseases risk factors: steps survey Nepal 2013. Kathmandu, Nepal: Nepal Health Research Council, 2014.

23 Nepal Health Research Council. Population based prevalence of selected non-communicable diseases in Nepal. Kathmandu, Nepal, 2019.
24 Dhimal M, Karki KB, Sharma SK, et al. Prevalence of selected chronic non-communicable diseases in Nepal. J Nepal Health Res Counc 2019;17:394-401.

25 Poudel M, Bhandari R, Malla G, et al. Rose angina questionnaire: validation in emergency department to detect myocardial infarction in a tertiary hospital of eastern Nepal. Hong Kong J Emer Med 2020;27:257-61.

26 Victora CG, Huttly SR, Fuchs SC, et al. The role of conceptual frameworks in epidemiological analysis: a hierarchical approach. Int $J$ Epidemiol 1997;26:224-7.

27 Singh K, Patel SA, Biswas S, et al. Multimorbidity in South Asian adults: prevalence, risk factors and mortality. J Public Health 2019;41:80-9.

28 Khan N, Rahman M, Mitra D, et al. Prevalence of multimorbidity among Bangladeshi adult population: a nationwide cross-sectional study. BMJ Open 2019;9:e030886.

29 Rizza A, Kaplan V, Senn O, et al. Age- and gender-related prevalence of multimorbidity in primary care: the Swiss fire project. BMC Fam Pract 2012;13:113.

30 Ruel G, Lévesque J-F, Stocks N, et al. Understanding the evolution of multimorbidity: evidences from the North West Adelaide health longitudinal study (NWAHS). PLoS One 2014;9:e96291.

31 Harrison C, Henderson J, Miller G, et al. The prevalence of complex multimorbidity in Australia. Aust N Z J Public Health 2016;40:239-44.

32 Araujo MEA, Silva MT, Galvao TF, et al. Prevalence and patterns of multimorbidity in Amazon region of Brazil and associated determinants: a cross-sectional study. BMJ Open 2018;8:e023398.

33 Ba NV, Minh HV, Quang LB, et al. Prevalence and correlates of multimorbidity among adults in border areas of the central highland region of Vietnam, 2017. J Comorb 2019;9:2235042X19853382.

34 Nguyen H, Manolova G, Daskalopoulou C, et al. Prevalence of multimorbidity in community settings: a systematic review and meta-analysis of observational studies. J Comorb 2019;9:2235042X1987093

35 Pandey AR, Karki KB, Mehata S, et al. Prevalence and determinants of comorbid diabetes and hypertension in Nepal: evidence from non communicable disease risk factors steps survey Nepal 2013. J Nepal Health Res Counc 2015;13:20-5.

36 Tripathy JP, Thakur JS, Jeet G, et al. Prevalence and determinants of comorbid diabetes and hypertension: evidence from non communicable disease risk factor steps survey, India. Diabetes Metab Syndr 2017;11(Suppl 1):S459-65.

37 Biswas T, Townsend N, Islam MS, et al. Association between socioeconomic status and prevalence of non-communicable diseases risk factors and comorbidities in Bangladesh: findings from a nationwide cross-sectional survey. BMJ Open 2019;9:e025538.

38 Pefoyo AJK, Bronskill SE, Gruneir A, et al. The increasing burden and complexity of multimorbidity. BMC Public Health 2015;15:415.

39 Jindai K, Nielson CM, Vorderstrasse BA, et al. Multimorbidity and functional limitations among adults 65 or older, NHANES 2005-2012. Prev Chronic Dis 2016:13:E151.

40 Ministry of Health, New ERA, ICF. Nepal demographic and health survey 2016. Kathmandu, Nepal: Ministry of Health, Nepal, 2017.

41 Brunner FJ, Waldeyer C, Ojeda F, et al. Application of non-HDL cholesterol for population-based cardiovascular risk stratification: results from the multinational cardiovascular risk Consortium. Lancet 2019;394:2173-83

42 Leijten FRM, Struckmann V, van Ginneken E, et al. The SELFIE framework for integrated care for multi-morbidity: development and description. Health Policy 2018;122:12-22. 